\title{
DE LA DOGMÁTICA AL REALISMO JURÍDICO EN LA TEORÍA DE LOS HECHOS Y ACTOS JURÍDICOS
}

\author{
From dogmatic to legal realism in the theory of facts and legal acts \\ Dalla dogmatica al realismo giuridico nella teoria dei fatti \\ e degli atti giuridici
}

Gabriel Limodio ${ }^{1}$

Para citar este artículo:

Limodio, G. (2020). "De la dogmática al realismo jurídico en la teoría de los hechos y actos jurídicos”. Prudentia Iuris, N. Aniversario, pp. 281-297. DOI: https://doi.org/10.46553/prudentia.aniversario.2020.pp.281-297

Resumen: El texto se refiere a la denominada teoría de los hechos y actos jurídicos, y propone una lectura del tema en la nueva codificación civil y comercial de la Nación Argentina en cuanto la misma pareciera diferenciarse de los modelos de la dogmática jurídica, criticando la figura de la pandectística. Ello permite trabajar una hipótesis leyendo el tema en una posición cercana a lo que fue el proceso jurisprudencial que modificó el planteo del codificador original, en cuanto proponía una mayor incidencia de la autonomía de la libertad y el individualismo, abriendo paso a la interpretación a partir de principios jurídicos.

Palabras clave: Teoría de los hechos y actos jurídicos; Dogmática jurídica; Pandectística; Principios jurídicos; Orden público.

Abstract: This article refers to the so-called theory of facts and legal acts, and proposes a reading of the subject in the new civil and commercial codi-

1 Doctor en Ciencias Jurídicas por la Universidad Católica Argentina, Buenos Aires, Argentina. Secretario Académico de la Universidad Católica Argentina, Buenos Aires, Argentina. Correo electrónico: gabriel_limodio@uca.edu.ar. 
fication of the Argentine Nation insofar as it seems to differ from the models of legal dogmatics, criticizing the figure of pandectistics. This allows working a hypothesis by reading the topic in a position close to what was the jurisprudential process that modified the original codifier's approach in that it proposed a greater incidence of the autonomy of freedom and individualism, opening the way for interpretation from legal principles.

Keywords: Theory of the facts and legal acts; Legal dogmatics; Pandectistics; Legal principles; Public order.

Sommario: Il testo fa riferimento alla cosiddetta teoria dei fatti e degli atti giuridici, e propone una lettura del soggetto nella nuova Codificazione Civile e Commerciale della Nazione Argentina in quanto sembra differire dai modelli della dogmatica giuridica, criticando la figura della pandettistica. Ciò consente di lavorare su un'ipotesi leggendo il soggetto in una posizione vicina a quello che è stato il processo giurisprudenziale che ha modificato l'approccio del codificatore originario in quanto proponeva una maggiore incidenza dell'autonomia della libertà e dell'individualismo, aprendo la strada a un'interpretazione basata su principi legali.

Parole chiave: Teoria dei fatti e atti giuridici; Dogmatica legale; Pandettistica; Principi legali; Ordine pubblico.

\section{Introducción}

Una vez más tengo que agradecer, a las autoridades de la Revista, la delicadeza de permitirme colaborar en un nuevo aniversario de nuestra Prudentia Iuris.

Digo nuestra porque para aquellos que tenemos el honor de ser graduados de la Facultad de Derecho de la Pontificia Universidad Católica Argentina y además docentes y en alguna oportunidad directivos de la misma, recordamos siempre el momento en que vimos nacer esta revista.

Lo importante es la celebración, el tema que se aporta bien puede ser una excusa, como en este caso se trata simplemente de una propuesta para releer la cuestión de la teoría de los hechos y actos jurídicos en clave realista.

Precisamente al cumplirse treinta y cinco años nuestra revista, decía que era muy difícil no recordar aquellos años de vida universitaria y lo que significa y ha significado que una publicación se haya mantenido con vida y siempre actualizada a través del tiempo, y asimismo se recordaba que desde su mismo nombre se daba una pauta de lo que significaba la enseñanza 
del Derecho en nuestras aulas como un saber sobre lo justo, que se alcanza observando la prudencia de cada caso concreto ${ }^{2}$.

Para homenajearla parece adecuado aportar un breve comentario sobre un tema que, con la puesta en vigencia del nuevo Código Civil y Comercial unificado, cobra fuerza, sin desconocer que todo aporte que se haga no puede sino ser provisorio. Van entonces unas palabras que pueden servir como introducción a la explicación de los hechos y actos jurídicos.

\section{El tema}

Se decía también cinco años atrás que "si fijamos una mirada retrospectiva, advertimos que, al tiempo del nacimiento de nuestra revista, es decir, la década del ochenta del siglo XX, se producían dos acontecimientos, que necesariamente influyen en la cuestión que tratamos. Por supuesto que los mismos no son excluyentes, pero muchas de las cuestiones que hoy inciden en la nueva formulación del Derecho Privado tienen que ver con ellas. Nos referimos a la consolidación del Estado de Derecho constitucional y la vigencia del tiempo cultural de la posmodernidad"3.

Pueden aparecer otras consideraciones, pero si se fija la mirada en los últimos acontecimientos que nos ocupan, se advierte que la denominada constitucionalización del Derecho Privado puede leerse desde dos aportes, ya que, por un lado, en aquel momento histórico quedaba definitivamente desenmascarado el positivismo y el denominado Estado de Derecho Legal, y por otro lado, lo que pudo interpretarse como el retorno del Derecho Natural culturalmente puede malograrse al imponerse un modelo en cual no exista reconocimiento de valores objetivos.

Como puede observarse a cinco años de haber hecho esa ponderación, y cuando nos aproximamos a los cinco años de vigencia del nuevo Código, pareciera que en lo que tiene que ver con la cuestión referida a las personas y sus derechos la situación se acerca claramente a una mirada individualista, lo cual es distinta a aquella que se aplica a otras partes del Código.

El tema, si bien puede referirse a la mirada actual sobre el Derecho Privado codificado, puede puntualizarse sobre el Código Civil y Comercial vigente en la República Argentina que, en una primera lectura, parece invertir la lógica que tuvo Vélez Sarsfield.

2 Resulta ocioso recordar que Prudentia Iuris siempre ha dedicado espacios a estudiar la evolución del Derecho Privado. A modo de ejemplo, Casares, T. (1945). Extracto del libro La Justicia y El Derecho. Prudentia Iuris nro. 1, Buenos Aires, Educa, 5-7.

3 Limodio, G. (diciembre 2015). "El Derecho Privado entre dos bicentenarios". Prudentia Iuris nro. 80, Buenos Aires, Educa, 19. 
Desde tal perspectiva, una manera de encarar la cuestión puede hacerse desde el contenido de la autonomía de la voluntad, que en determinados casos pareciera que ha tenido una mirada exclusivamente desde el ámbito contractual, recordando así el antiguo artículo 1197 del Código. Sin embargo, ahora se ha ampliado a aquellas cuestiones que hacen al concepto sobre la persona y la familia, valorando de una manera muy particular el concepto de proyecto de vida.

Por eso se ha elegido hablar del paso de la dogmática al realismo, aprovechando que el término dogmática jurídica es sugerido por la Comisión Reformadora del Código de 2012, al tiempo que se pronuncia contra la figura del pandectismo, como método para elaborar, aplicar y enseñar el Derecho.

Por lo pronto, cabe plantearse la verdadera esencia de lo que significa el Derecho Privado, para conocer sus límites pero también sus riquezas, y proponer una nueva lectura de las realidades que encierra. Surge aquí el recuerdo del formidable jurista Guillermo Borda, quien al prologar un trabajo sobre derechos personalísimos decía: "Ha sido Josserand quien ha dicho que el Derecho Civil es el derecho por excelencia, el armazón mismo y la base de la juridicidad. Quizá ningún otro tema revele en toda su hondura la verdad de esta afirmación como el de los derechos de la personalidad. Aquí el Derecho Civil está presente, si se me permite la expresión, en estado puro. Se trata de los derechos primarios, esenciales, del hombre: el derecho a la vida, a la integridad física, a la libertad, al honor, al respeto, a la privacidad. Es decir, los derechos de los que nadie puede ser privado sin lesionar el orden natural"4.

Para ilustrar también de una manera elegante aquello que se quiere significar parece oportuno citar un texto de uno de los civilistas más caracterizados de nuestro tiempo, Jorge Alterini; al prologar su obra, el Código Civil y Comercial Comentado, dice: "Nos han enseñado y hemos enseñado el Derecho Privado cobijados por la personalidad emblemática de Vélez Sarsfield, que dejó su impronta no sólo en el Código Civil de 1871, sino también en el Código de Comercio de 1859 de la Provincia de Buenos Aires, posteriormente convertido en Código de la Nación. Aprendimos de él y de quienes supieron enriquecerse con sus mensajes genuinos, que la autonomía de la voluntad era un estímulo inagotable de las relaciones económico-sociales, pero también que los intereses particulares debían subordinarse al bien común y a la necesidad de recrear la justicia a través de su vehículo hacia lo concreto: la equidad". Y continúa: "Estos textos codificados y muchas de las importantes modificaciones que recibieron no son ya Derecho vigente, los

4 Borda, G. (2008). "Prólogo a la Primera Edición de Santos Cifuentes, Derechos Personalísimos”. Reproducido en la $3^{\mathrm{a}}$ edición. Buenos Aires. Astrea, XI/XII. 
ha desplazado la reclamada unificación civil y comercial, y así nuevas realidades irrumpieron en nuestra comunidad que dieron contenido al Código Civil y Comercial, no todas son variados rostros de verdaderos paradigmas, o sea, con la ejemplaridad de los modelos, pero sí con la fuerza desbordante de las matizaciones vitales"5.

Precisamente este texto citado permite pensar en la trayectoria que se recorrió desde la obra singular de Vélez Sarsfield al Código Unificado, con una mirada sobre dos momentos significativos, como fueron la reforma de 1968 y el Proyecto de 1998, del cual el nuevo Código reprodujo la mayor parte de sus artículos pero no necesariamente su espíritu.

La pregunta que queda para responder, o por lo menos para reflexionar, es si un código refleja una situación que sucede en la realidad y le da contenido jurídico, o si se sobrepone al mero suceder y propone un verdadero paradigma que no tenga más que un anclaje en lo subjetivo.

Otra forma de formular la pregunta sería: un código reúne preceptos, estos preceptos ¿reflejan un determinado ethos que ya existe, o crean uno nuevo a partir de lo que creen o interpretan los legisladores, y luego los jueces?

Desde la perspectiva planteada en los primeros párrafos, corresponde centrarse en la idea de que ha habido un desplazamiento del centro jurídico de la noción de persona a la de individuo.

Por fin cabe referirse a otro modelo de codificación, más complejo, propio de una época multicultural, podríamos decir posmoderna, donde nos encontramos con un código de textura abierta.

Esta frase es importante, porque es prácticamente una autodefinición del código. Esto se encuentra en "Los Fundamentos de la Comisión Redactora" y también en todas las ediciones que se publican del Código.

Se hace esta consideración porque como es sabido los códigos actuales no tienen notas, por lo tanto, para conocer el origen doctrinario de la norma se debe recurrir a los fundamentos escritos por la Comisión Redactora del Código. También puede resultar de utilidad la nota introductoria a todas las ediciones del Código preparada por el presidente de la Comisión, Dr. Lorenzetti. Es allí donde se encuentra este postulado de un código de textura abierta merced a una pluralidad de fuentes, y una mirada distinta a lo que fue el código del siglo XIX. Así, dice Lorenzetti en la introducción al Código Civil y Comercial, en el capítulo "Paradigmas y Principios": "[...] un código del siglo XXI se inserta en un sistema caracterizado por el dictado incesante de leyes especiales, jurisprudencia pretoriana y pluralidad de fuentes. La

5 Alterini, J. H. (Director General) (2016). Código Civil y Comercial Comentado. Tratado Exegético. Prólogo a la Primera Edición. Buenos Aires. Thompson Reuters-La Ley, XIII. 
relación entre un código y los microsistemas jurídicos es la del sol que ilumina cada uno de ellos y que los mantiene dentro del sistema. Lo importante es entonces que el Código defina los grandes paradigmas del Derecho Privado a través de principios que van estructurando el resto del ordenamiento, y esa es la proposición metodológica central de este proyecto [...] sin embargo, la potencialidad de los principios irá reformulando el sentido de cada uno de los microsistemas, tarea que incumbe a la doctrina y jurisprudencia. Sin perjuicio de ello, se mantuvieron una serie de reglas de extensa tradición en el Derecho Privado porque constituyen una plataforma conocida, a partir de la cual se producen las mudanzas hacia los nuevos tiempos, se ha pensado en el ciudadano y por eso los paradigmas y principios responden a las prácticas sociales vigentes, todo lo cual se expresa en el lenguaje más claro posible"6.

Por otra parte, una cuestión que cabe tener en cuenta es la incorporación de un título preliminar, al cual se le ha dado la función de un "núcleo de significaciones", con lo cual se abre una instancia muy distinta a la que estamos acostumbrados y también se abre una posibilidad, ya que el Código habla de valores, de principios jurídicos, no de principios generales del Derecho; distingue Derecho de ley, tal como lo había hecho el Proyecto de 1998.

\section{Dogmática y realismo}

Si se retoman las frases a las que se ha hecho referencia más arriba, en cuanto a lo que se pretende con este "núcleo de significaciones", esta misma es toda una declaración de principios; más aún vale la pena, para explicar este salto del positivismo a otras formas más cercanas a la realidad, transcribir una frase del texto introductorio al Anteproyecto firmado por la Comisión Reformadora: “[...] una de las funciones que puede cumplir un Título Preliminar es la de aportar algunas reglas que confieren una significación general a todo el código. De este modo, el sistema adquiere un núcleo que lo caracteriza y que sirve de marco de comprensión de una gran cantidad de cuestiones de interpretación y de integración de lagunas. No se trata de una parte general al modo en que fuera pensado en la pandectística alemana, sino del diseño de unas líneas de base enfocadas en la argumentación jurídica razonable dentro de un sistema de derechos basados en principios y valores"7.

6 Lorenzetti, R. (2015). Introducción al Código Civil y Comercial de la Nación. Texto aprobado por Ley $N^{\circ}$ 26.994. Buenos Aires. Editorial El Derecho.

7 Fundamentos del Anteproyecto del Código Civil y Comercial de la Nación, III pto. 3. 
Si bien en el texto citado se utiliza la palabra pandectismo, teniendo en cuenta que el mismo se refiere a un análisis del Derecho romano buscando sistematizarlo y extraer principios generales, se ha generalizado en el término dogmática, que es la ciencia de un Derecho Positivo vigente, que investiga la conexión entre cada una de las normas jurídicas y siempre se la ha vinculado al modelo del positivismo, no solamente al que ha imperado a partir de las primeras décadas del siglo XX, sino al que hunde sus raíces en la Ilustración, se encuentra formulada filosóficamente en el voluntarismo de la Escuela Moderna del Derecho Natural y finalmente explica el Derecho Civil desde la Escuela de la Exégesis y el Código Civil francés de 1804. No puede descartase la referencia al Código Civil alemán de 1900 por su fuerte impronta científica ${ }^{8}$.

De acuerdo con su fin, la dogmática prepara la aplicación, además sirve para la presentación del Derecho Positivo en la enseñanza; en un intento de simplificar la cuestión, si se desecha la manera de entender y explicar el Derecho desde la dogmática jurídica, no cabe sino un método clásico.

Precisamente, en el nivel del conocimiento, cabe concebir una etapa anterior a la sistematización, que genera como producto el denominado saber ordinario, que se caracteriza porque en su generación se carece de un método preciso; el método aparece después y es el que conferirá el carácter de ciencia. Esta última es precisamente la explicación de un segmento de la realidad en forma directa, expresada en lenguaje riguroso y literal, mediante proposiciones enunciativas susceptibles de demostración siguiendo las reglas de la lógica formal, que vinculan a la realidad con sus principios y causas, que a su vez puede ser sometida a crítica racional. Así la demostración relativa al objeto es lo que forma la teoría, que implica un camino para conocer su naturaleza.

Desde tal enfoque, si se busca enseñar Derecho Privado desde una perspectiva clásica parece razonable deshacerse del nombre de "Parte General" y referirse a "Principios de Derecho Privado e Instituciones", y cuando se fijan los temas por desarrollar, hablar de la persona y de la relación jurídica, entendiendo esta como un vínculo correlativo entre dos o más sujetos, con un objeto determinado y fundamentado en el Derecho ${ }^{9}$.

De allí entonces la propuesta como hipótesis de trabajo de entender el Título Preliminar como un núcleo de significaciones que, como un conjunto

8 Tobías, J. W. (2018). Tratado de Derecho Civil. Parte General. I. I. Buenos Aires. Thomson Reuters-La Ley, 41.

9 Vigo, R. (2012). "Comentarios al Capítulo 1 del Título Preliminar”. En Análisis del Proyecto de Nuevo Código Civil y Comercial 2012. Compilador: Jorge Nicolás Lafferriere. Buenos Aires. Ed. El Derecho, 63 y sigs. Limodio, G.; Barbieri, J. (2006). Introducción al saber jurídico. Buenos Aires. EDUCA, 108 y sigs. 
de principios y valores, iluminan la interpretación del Código, y a partir de allí, la antigua Parte General. Con una denominación más propia, la manera de estudiar el Derecho Privado contará con una parte introductoria, donde se desarrolla la cuestión del Derecho, su enseñanza, su codificación, fuentes e interpretación, para luego referirse a cada uno de los elementos de la relación jurídica.

Cuando se trata puntualmente de hablar de la relación jurídica, y de su causa, una visión clásica se referirá al ordenamiento jurídico, que implica una mirada superadora de lo que oportunamente fue la teoría de los hechos y actos jurídicos. En esta línea, la perspectiva sobre el ordenamiento jurídico se torna dinámica, y no corresponde a una definición solamente teórica. Desde esta mirada, la vida en la ciudad trata de ser un microcosmos, la convivencia entre sus habitantes deberá desarrollarse de manera coherente, tratando de acordar entre autonomía de la voluntad y orden público, resguardando una manera tradicional de entender el bien común. Así las leyes e instituciones no son más que medios y canales para permitir y llevar adelante un tipo de vida que genere una forma de virtud que podría identificarse con la que el pensamiento clásico llama conmutativa ${ }^{10}$.

En este contexto la justicia humana será la perfección de la voluntad en orden a dar al otro lo que es suyo de él y este suyo es lo que se llama justo. La función del juez no será buscar lo justo en medio de la contienda del mercado y la lucha política; su función es, básicamente, la corrección, la enmienda de los excesos que pueden generarse en los negocios y en el foro, restaurar los equilibrios y favorecer el mantenimiento de la paz. De allí que se sostenga que el Derecho es un saber, y dentro de la categoría de éste, es un saber práctico, y se debe decir, con insistencia, práctico prudencial.

Aquí vuelve a cobrar importancia el tema de los principios en general, para luego pasar a la cuestión de los principios jurídicos. Se dice esto pues la cuestión de la denominada "teoría general" de los hechos y actos jurídicos, en el actual Código, ha pasado a formar parte del Libro Primero, llamado todavía de una manera equívoca "Parte General", pero en la cual de una u otra forma se refiere a aquello que podemos considerar como la parte constitutiva del Derecho Privado, ya que es el desarrollo de la relación jurídica; dicho de otra manera, el desenvolvimiento de cada uno de sus elementos. Cobra vigencia entonces leer el Título Preliminar, como se dijo más arriba, como núcleo de significaciones, cuyos contenidos se trasladan a todo el campo del Código, lo cual no implica necesariamente seguir la opinión de los legisladores, sino proponer una lectura desde el realismo jurídico.

10 Sanz, C. R. (2019). Lecciones de Filosofía del Derecho. Buenos Aires. Ed. El Derecho, Lección VI. 
De esta manera, para no caer en un mero pronunciamiento teórico, comprender la causa de la relación jurídica obliga a una lectura en conjunto de la autonomía de la voluntad y el orden público, por un lado, y, por otro lado, una lectura del Derecho Privado y el Derecho Público.

\section{Autonomía de la voluntad-orden público. Derecho Público-Derecho Privado}

Una de las transformaciones profundas del Derecho Privado es una suerte de tendencia hacia una reivindicación siempre más amplia de los derechos individuales, que esconde una concepción de la persona desligada de todo contexto social a partir de un llamativo avance de la autonomía de la voluntad. Si bien la misma es una dimensión fundamental de la dignidad humana, no puede ser entendida en un sentido absoluto, de tal forma que legitime acciones que agredan las bases de la convivencia social y conduzca a formas radicalizadas de individualismo que no corresponden a la dimensión relacional de la persona humana.

Para comprender esta tendencia podría pensarse en un término utilizado de manera equívoca: "ética de los derechos", es decir, aquella ética en la que los derechos son el valor prioritario y dominante, y en la que, por tanto, la cuestión fundamental no consiste en establecer si una acción es buena $o$ debida, sino si se tiene o no el derecho a realizarla. Por el contrario, parece legítimo hablar de una ética de los derechos cuando éstos están cargados de una connotación moral.

A este respecto ha sostenido Francesco Viola que "muy pocos de los valores e ideales del pasado pueden alcanzar el consenso universal que se les reconoce hoy en día a los derechos. No es el caso de referirse al hecho de que los derechos sean objeto de tratados internacionales o de declaraciones 'universales', pues los unos y las otras son a menudo ocasión para la hipocresía y la reserva mental, sino que cabe pensar en el derecho a la propia identidad individual y colectivo, defendido frente a quien tiene una identidad claramente distinta. Esto supone que en un régimen pluralista la única posibilidad de comunicación entre las distintas familias culturales, ideológicas y espirituales parezca darse precisamente en los derechos. No se comprenden entre ellas, son todavía mundos cerrados en sí mismos pero, sin embargo, pueden llegar a comprender qué significa respetar los derechos del otro, del distinto, porque saben que significa exigir y tener el respeto a los propios derechos"11.

11 Viola, F. (1999). “La ética de los derechos”. Doxa Nro. 22, 507-524. 
La constatación de que los derechos se han convertido en el lenguaje para la comunicación entre individuos de distintas culturas en el régimen del pluralismo no significa, no obstante, que pueda hablarse de una ética de los derechos; es decir, de una ética alternativa a la del bien, de lo debido o de lo útil. El consenso universal, en relación con la posibilidad de interpretar los derechos como la consolidación de una verdadera y propia "ética", es muy problemático por muchas razones. Si hubiese que encontrar un título para ejemplificar este nuevo paradigma podría situarse en la creación de un "Estado de Derechos", pero en verdad lo que puede colegirse es la aparición de una versión del neoconstitucionalismo desde una perspectiva constructivista de la ética ${ }^{12}$.

Si se quiere analizar desde la perspectiva del iusprivatismo, otra manera de plantear la cuestión es ubicarla en la tensión entre orden público-autonomía de la voluntad. Puede plantearse que, dentro del marco del Derecho Privado, el orden público es aquel que asegura el funcionamiento de dicho ordenamiento. Así, desde la Filosofía del Derecho, Rodolfo Vigo encuentra en el orden del Derecho Positivo privado, en especial referencia al Código Civil, más allá de artículos específicos, una suerte de componente jurídico que tiende a asegurar bienes y valores en los que aparecen claramente comprometidos el bien común y el interés público. En este sentido, toda norma de orden público presupone la preservación de un determinado aspecto del bien común, sin el cual carecería de fundamento y devendría arbitraria ${ }^{13}$.

Tal como Vigo lo ha definido, el orden público es la articulación en lo público de las personas y la sociedad infrapolíticas para alcanzar el bien común político ${ }^{14}$.

A partir de esta definición puede arrojarse una mirada sobre lo que se denomina "orden público", y se advierte que aquí aparece una situación muy conectada con la que puede estudiarse cuando se analiza la llamada "cuestión de los principios generales del Derecho". Es decir, la noción resulta objeto de muy diversas consideraciones según nos aproximemos a ella desde la perspectiva iusnaturalista clásica o bien desde el positivismo jurídico. En el

12 Vigo, R. (2012). "Derecho y Moral en el Estado de Derecho constitucional. (Proyecciones teóricas: iuspositivismo, neoconstitucionalismo y realismo jurídico clásico)". Prudentia Iuris nro. 74, Buenos Aires, Educa, 57-78.

13 Vigo, R. trabaja sobre la obra, “Orden público y orden público jurídico”, publicada en JA T. 1985 -IV- 675, y también del mismo autor (2015). Iusnaturalismo y Neoconstitucionalismo. Buenos Aires. Educa, capítulo 23. Además, puede consultarse la obra de Díez Picazo - Gullón (2000). Sistema de Derecho Civil. $2^{\text {a }}$ reimpresión. Tecnos, 2000, en especial el capítulo de la autonomía privada, 373 y sigs.

14 Vigo, R. Ob. cit., ver nota anterior. No está de más citar que el número 3 de la Revista Prudentia Iuris fue dedicado totalmente a la noción de "Bien Común", número de abril de 1981. 
caso de los llamados "principios generales del Derecho", los mismos difieren de los denominados "principios jurídicos", por la influencia del positivismo jurídico, y por lo mismo, por la forma de enseñar a partir de la escuela de la exégesis ${ }^{15}$.

Cabe recordar que en materia de Derecho Privado, y sobre todo después de la experiencia exegética-dogmática-iuspositivista, se hace visible la convicción de ciertas normas "evidentes y palpables" que los teóricos del siglo XIX traducen por Derecho Natural, y que es "una colección de reglas que es necesario y deseable traducir inmediatamente en leyes positivas"16.

De esta manera, el problema del orden público, en la clave del positivismo, pasa a ser el de la síntesis del ordenamiento jurídico positivo. Así, los principios jurídicos son los principios generales del Derecho, en cuanto son los presupuestos del Derecho emanado de la razón del legislador y de allí que en muchos casos se hable de "leyes de orden público".

Lo cierto es que el orden público de una comunidad no puede emanar de su ordenamiento positivo vigente, sencillamente porque no cabe confundir el Derecho con la ley positiva, ni tampoco fundamentar el origen del mismo en la razón de la persona. Esta manera de entender el Derecho Natural desde la perspectiva del racionalismo es la que genera la inclusión del mismo en las codificaciones del siglo XIX y la que mostrará una plenitud del ordenamiento jurídico positivo, que será enseñado por los doctrinarios de la exégesis. No es casualidad que tanto el tema de los principios generales del Derecho como el de la moral y las buenas costumbres y el orden público se incluyan en la interpretación de la ley, y se enfatice la frase "interpretación de la ley", cuando de lo que se debe hablar es de interpretación jurídica.

El orden público, en cuanto refleja el fin del Derecho, que es el bien común, se funda en cuestiones objetivas que superan el relativismo de aceptar lo que piensa el legislador o una mayoría en un momento determinado. Hablar de la dignidad de la persona o del bienestar general son realidades concretas que pueden ser discernidas en la medida en que se acepte la verdad que surge de la naturaleza de las cosas. En este marco, parece conveniente repasar cómo se define el orden público en las obras dedicadas a la enseñanza. En un breve repaso por las definiciones, se cita la que ofrece Salvat, quien sostiene: “[...] la noción de orden público es la que surge de un

15 Vigo, R. (2000). Los principios jurídicos, perspectiva jurisprudencial. Buenos Aires. Depalma.

16 Respecto a estos temas se sigue el desarrollo de Leon Husson en su obra (1972). Analyse critique de l'ecole de la exégése. Paris Sirey. APD, XIII, p. 115. Para el tema específico del Derecho Natural en la codificación resulta interesante la consulta del capítulo "El problema del Derecho Natural", en la obra de Leclercq, J. (1965). El derecho y la sociedad. Sus fundamentos. Barcelona. Biblioteca Herder, 19 y sigs. 
conjunto de principios fundamentales de orden político, filosófico, económico, moral y algunas veces religioso, cuya observancia se considera esencial para la existencia y conservación de la organización social establecida"17.

Borda, por su parte, prefiere hablar de disposiciones de orden público al afirmar que las mismas son tales cuando "en el cumplimiento de esa ley media una cuestión de orden social colectivo o un interés público"18.

Para Arauz Castex, la expresión alude a una categoría o clase de disposiciones de fundamental interés para el pueblo, para la Nación, para la sociedad entera. Cifuentes prefiere hablar de leyes de orden público dentro del capítulo de la norma y reconoce que existe una doctrina muy extendida según la cual se identifica al mismo con un conjunto de principios eminentemente superiores, sobre cuya base se asientan la paz, la seguridad social, las buenas costumbres, la justicia y la moral. Sin embargo, a renglón seguido se interroga cuáles son esos principios, quién los establece y qué leyes los contienen, con lo cual agrega una dosis de escepticismo. Concluye que las leyes que están identificadas con el orden público son las que según la sociedad de que se trate suelen considerarse imperativas, por lo que su fuerza de imposición está vinculada al interés colectivo o general.

De alguna manera este criterio es también el que sugieren Belluscio y Zannoni al hablar de un "estándar jurídico" para la moral y para las buenas costumbres, que tenga que ver con la aceptación por parte de la mayoría de la sociedad en un momento determinado, a pesar de que estos autores, siguiendo a Brocher, identifican el orden público como "la restricción a la autonomía de la voluntad que, con sentido de equidad, ampara al interés general de la sociedad, para la realización de una idea de justicia"19.

Llambías se inclina por la definición clásica al hablar del "conjunto de principios eminentes -religiosos, morales, políticos y económicos- a los cuales se vincula la digna subsistencia de la organización social establecida" ${ }^{20}$.

Ciertamente, la noción de orden público, tal como lo expresa Llambías, puede resultar equívoca. Sin embargo, si nos atenemos a la derivación de orden público a partir del fin de la sociedad política, el sustento de dicho orden no variará por la opinión de una sociedad en un momento determinado, sino que radicará en valores que no son sustituibles por una u otra opinión de la voluntad general. Se advierte una vez más la importancia de identificar el orden público con principios jurídicos que no son los del positivismo,

17 Salvat, R. (1958). Tratado de Derecho Civil Argentino. T. I. Buenos Aires. TEA, 168.

18 Borda, G. (2000). Tratado de Derecho Civil, Parte General. Buenos Aires. Lexis Nexis.

19 Zannoni, B. (1993). Código Civil Comentado Anotado y concordado. Buenos Aires. Astrea, p. 66.

20 Llambías, J. (1999). Tratado de Derecho Civil, Parte General. Buenos Aires. Editorial Abeledo-Perrot, 139 . 
ya que radican en la naturaleza de la persona humana, que es fundante del orden jurídico. Cobra así vigencia la definición de la relación jurídica, en cuanto reconoce como causa de la misma el propio ordenamiento jurídico. Y este último consiste en una síntesis de deberes y derechos que radican en lo objetivo, porque tanto la naturaleza de las cosas, a la que se hizo referencia, como el bien común político se sustentan en valores externos a la razón del hombre.

En suma, el orden público, entendido a su vez como un límite de la autonomía de la voluntad, debe leerse en forma complementaria con la visión amplia de principios jurídicos a la que se viene haciendo referencia.

Para concluir con esta rápida mirada sobre la doctrina, es importante destacar el comentario que a este instituto hace Lorenzetti, quien respecto al nuevo Código dice que el orden público es regulado mediante una cláusula general, que implica un límite al ejercicio de los derechos individuales fundado en razones generales ${ }^{21}$. El autor se refiere a algunos ejemplos:

- El orden público como garantía procedimental al consentimiento pleno: consiste en una serie de dispositivos destinados a garantizar que efectivamente se exprese la autonomía privada; el legislador se ocupa de que exista un consentimiento pleno, una garantía del proceso de formación del acto jurídico.

- El orden público de protección de la parte débil: las partes pueden haber emitido correctamente su declaración pero hay una vulnerabilidad económica o cognoscitiva que lleva a proteger a la parte débil. La intervención tiene vocación de permanencia; no es coyuntural o transitoria. No es una intervención que distorsiona la autonomía, sino que la mejora, fortaleciendo la igualdad. Por ello es una garantía procesal y objetiva en la igualdad de oportunidades para expresar la voluntad. Un claro ejemplo de ello son las normas de tutela del consumidor (arts. 1092 y concs.).

- El orden público de coordinación: es un conjunto de normas imperativas que controla la licitud en el ejercicio de los derechos, principalmente su adecuación a los valores esenciales del ordenamiento jurídico. Un ejemplo de ello son las propias normas sobre la sociabilidad en el ejercicio de los derechos. Se diferencia del orden público de dirección, porque lo que éste se propone es lograr objetivos económico-sociales, y su límite es justamente este orden público constituido por las garantías mínimas.

21 Lorenzetti, R. (2014). Código Civil y Comercial de la Nación Comentado. T. I. Santa Fe. Rubinzal-Culzoni, 68. 
El último tema que se debe analizar es el del orden público en su relación con el Derecho Público, y la influencia de dicho orden en el Derecho Privado.

$\mathrm{Al}$ escapar de la trampa del positivismo jurídico es necesario remarcar que, al hablar de Derecho, se lo está haciendo en el marco de un concepto común, que encierra las tres acepciones o analogados posibles (el principal, lo justo y los secundarios, norma y facultad). Sin embargo, es importante destacarlo porque al fundar la distinción de los sistemas público y privado del Derecho se ha tendido muchas veces a hacerlo con la mirada puesta sólo en uno de sus analogados: en la norma. Esto genera confusión, ya que, reducido el Derecho a la ley, se entendió por Derecho Público aquel que integra las normas de orden público o imperativo, y por Derecho Privado, aquel que comprende las normas de orden privado o dispositivo. Esta visión del problema es inexacta, ya que parte de un presupuesto erróneo ${ }^{22}$.

Por tal razón, hay que dejar claro que no debe confundirse Derecho Público con normas de orden público, ni Derecho Privado con normas dispositivas o de orden privado. Debe afirmarse, entonces, que las normas de orden público o imperativas son aquellas que dictadas con miras a un interés que trasciende la esfera de los particulares no admiten ser dejadas de lado por convenios privados realizados por aquellos que, en caso concreto, están llamados a observarlas. El fundamento por el cual se incluyen algunas normas como de orden público resulta de un conjunto de principios, valores y tradiciones que una sociedad considera estrechamente ligadas a su idiosincrasia y a su historia. Puede advertirse que reaparece aquí la noción de orden público, tal como se la definió más arriba. Es esta la que debe tenerse en cuanta al interpretarse el artículo 12 del Código Civil y Comercial, cuando éste sostiene que "las convenciones particulares no pueden dejar sin efecto las leyes en cuya observancia está interesado el orden público”.

\section{Intento de síntesis}

No cabe sino una síntesis provisoria de todo lo que se ha dicho, ya que toda posible conclusión queda abierta al debate, pues se parte de la intención de la Comisión Reformadora, que se mencionó más arriba, de no adherir a los postulados de la pandectística; desde esta perspectiva debe recordarse que forma parte de una pacífica doctrina que la teoría general de negocio jurídico es precisamente una construcción del pandectismo alemán del siglo XIX que intenta encontrar las reglas comunes a todo tipo de nego-

22 Limodio, G. y Barbieri, J. Introducción al saber jurídico. Ob. cit., 130 y sigs. 
cios jurídicos, y como también se dijo más arriba, sus raíces más profundas pueden encontrarse en la Escuela de Derecho Natural Moderno, que daba importancia al tema de la voluntad como fuente de efectos jurídicos y en la evolución del derecho de los contratos, en los cuales prevalece la figura de la autonomía de la voluntad.

En cuanto al tema puntual de los hechos, se sustituye en la definición el término derechos y obligaciones en el artículo 257, que se modifica por relaciones jurídicas. Al decir de Lorenzetti, "el Código define a los simples actos lícitos utilizando una fórmula similar a la del ordenamiento anterior. La única modificación radica en que se sustituye la referencia a la adquisición, modificación o extinción de derechos y obligaciones, por la de 'relaciones y situaciones jurídicas', a efectos de abarcar algo más que el derecho de las obligaciones y alcanzar no sólo a las relaciones patrimoniales sino también a las extrapatrimoniales y a las de carácter permanente-situaciones jurídicas-, y no sólo a las variables y contingentes, como ocurre con las relaciones jurídicas" 23 .

En el mismo sentido, el autor citado, refiriéndose al artículo 259, dice que "el acto jurídico es el acto voluntario lícito por el cual las personas regulan por sí mismas sus propios intereses en las relaciones con otros, en tanto el Derecho enlaza efectos conforme a la función que caracteriza a su tipo. Por supuesto, no siempre las condiciones o cláusulas quedan libradas a la voluntad de las personas, sino que esas pautas están fijadas por la ley. En tal caso, la voluntad de los sujetos es válida en tanto cumpla con la estructura y forma de ser del negocio jurídico, tal caso se encuentra previsto en el ordenamiento. En definitiva, conforme a una opinión que ha sido ampliamente aceptada, los actos jurídicos suelen estar integrados por una triple fuente de efectos jurídicos: la voluntad de las partes, el ordenamiento jurídico y, según el caso, la interpretación judicial"24.

Así, puede concluirse que todo lo que hace a la causa de la relación jurídica se mantiene dentro de la órbita que ha querido darle en su momento la Reforma del año 1968; no está de más recordar que el objeto de los actos jurídicos del nuevo artículo 279 mantiene los contenidos del antiguo artículo 953 , cuando se refiere a las prohibiciones de la ley, o contrarios a la moral, a las buenas costumbres, al orden público o lesivo de los derechos ajenos a la dignidad humana.

Por otra parte, las tres grandes instituciones generadas por aquella reforma como límite a la autonomía de la voluntad, como la lesión subjetiva, el abuso del Derecho y la teoría de la imprevisión, siempre fueron conside-

23 Lorenzetti, Raúl, Código.... Ob. cit. T. II, 17.

24 Ídem, 18. 
radas como verdaderos diques de contención ante cualquier intento individualista. A este respecto, cabe recordar la nota al artículo 943, cuando Vélez Sarsfield sostiene: "Finalmente dejaríamos de ser responsables de nuestras acciones, si la ley nos permitiera enmendar todos nuestros errores, o todas nuestras imprudencias. El consentimiento libre, prestado sin dolo, error ni violencia y con las solemnidades requeridas por las leyes, debe hacer irrevocables los contratos". Ahora no solamente se mantiene esta adecuada limitación, sino que se le da una estructura mejor. Por una parte, el abuso del Derecho pasa a ser una de los principios que ordenan todo el Código, al igual que la noción de orden público; basta con leer los artículos $9^{\circ}, 10$ y 11 .

Por otra parte, los artículos 1003 y 1004, referidos al objeto de los contratos, remiten al capítulo de actos jurídicos. La lesión se mantiene como vicio de la voluntad (art. 332) y la teoría de la imprevisión en el artículo 1091, en el capítulo de extinción, modificación y adecuación de los contratos; el nuevo artículo 1011 se refiere a la obligación de renegociar, como una derivación del deber de colaboración, tratando de evitar que una modificación en la situación de cualquiera de las partes genere una ruptura contractual.

Sirvan entonces estos ejemplos, para ensayar una lectura de la causa de la relación jurídica, ya consolidada con una dinámica que escapa a una mera estructura lógica, sino que adquiere una vida propia que permite diseñar un modelo social más equitativo en el ámbito de los intercambios de la ciudad.

Cabe siempre recordar lo que se decía en las primeras páginas de nuestra revista hace cuarenta años, "elaborar un pensamiento jurídico coherente con los principios de la justicia y el orden natural", el realismo jurídico tradicional no es nada más y nada menos que esto.

\section{Bibliografía}

Alterini, J. H. (Director General) (2016). Código Civil y Comercial Comentado. Tratado Exegético. Prólogo a la Primera Edición. Buenos Aires. Thompson Reuters-La Ley, XIII.

Borda, G. (2008). Prólogo a la Primera Edición de Santos Cifuentes "Derechos Personalísimos". Reproducido en la $3^{\text {a }}$ Edición. Buenos Aires. Astrea, XI/XII.

Borda, G. (2000). Tratado de Derecho Civil, Parte General. Buenos Aires. Lexis Nexis.

Leclercq, J. (1965). El Derecho y la sociedad. Sus fundamentos. Barcelona. Biblioteca Herder.

Limodio, G. (diciembre 2015). "El Derecho Privado entre dos bicentenarios". Prudentia Iuris, Nro. 80.

Limodio, G.; Barbieri, J. (2006). Introducción al Saber Jurídico. Buenos Aires. EDUCA.

Llambías, J. (1999). Tratado de Derecho Civil, Parte General. Editorial Abeledo-Perrot, 139. 
Lorenzetti, R. (2014). Código Civil y Comercial de la Nación Comentado. T. I. Santa Fe. Rubinzal-Culzoni Editores.

Lorenzetti, R. (2015). Introducción al Código Civil y Comercial de la Nación. Texto aprobado por Ley $N^{\circ}$ 26.994. Buenos Aires. Editorial El Derecho.

Salvat, R. (1958). Tratado de Derecho Civil Argentino. T. I. Buenos Aires. TEA.

Sanz, C. R. (2019). Lecciones de Filosofía del Derecho. Buenos Aires. Ed. El Derecho, Lección VI.

Tobías, J. W. (2018). Tratado de Derecho Civil-Parte General. T. I. Buenos Aires. Thomson Reuters-La Ley.

Vigo, R. "Orden público y orden público jurídico". En JA T. 1985 - IV - 675.

Vigo, R. (2000). Los principios jurídicos, perspectiva jurisprudencial. Buenos Aires. Depalma.

Vigo, R. (2012). “Comentarios al Capítulo 1 del Título Preliminar”. En Análisis del Proyecto de Nuevo Código Civil y Comercial 2012. Compilador: Jorge Nicolás Lafferriere. Buenos Aires. Ed. El Derecho.

Vigo, R. (2012). "Derecho y Moral en el Estado de Derecho Constitucional. (Proyecciones teóricas: iuspositivismo, neoconstitucionalismo y realismo jurídico clásico)". Prudentia Iuris Nro. 74.

Viola, F. (1999). "La ética de los derechos". Doxa Nro. 22.

Zannoni, B. (1993). Código Civil Comentado Anotado y concordado. Buenos Aires. Astrea. 